Der deutsche Roman der Moderne 


\author{
Jürgen H. Petersen
}

\title{
Der deutsche Roman der Moderne
}

Grundlegung - Typologie - Entwicklung

J. B. Metzlersche Verlagsbuchhandlung Stuttgart 
CIP-Titelaufnahme der Deutschen Bibliothek

\section{Jürgen H. Petersen:}

Der deutsche Roman der Moderne : Grundlegung - Typologie Entwicklung / Jürgen H. Petersen.

- Stuttgart : Metzler, 1991

ISBN 978-3-476-00782-7

ISBN 978-3-476-03380-2 (eBook)

DOI 10.1007/978-3-476-03380-2

Dieses Werk einschließlich aller seiner Teile ist urheberrechtlich geschützt. Jede Verwertung außerhalb der engen Grenzen des Urheberrechtsgesetzes ist ohne Zustimmung des Verlages unzulässig und strafbar. Das gilt insbesondere für Vervielfältigungen, Übersetzungen, Mikroverfilmungen und die Einspeicherung und Verarbeitung in elektronischen Systemen.

(C) 1991 Springer-Verlag GmbH Deutschland Ursprünglich erschienen bei J. B. Metzlersche Verlagsbuchhandlung und Carl Ernst Poeschel Verlag GmbH in Stuttgart 1991 


\section{Inhalt}

Einleitung

\section{ERSTER TEIL: GRUNDLEGUNG}

Die Entfaltung der Wirklichkeit als reine Möglichkeit in der Moderne

Epische Vermittlung reiner Möglichkeit: Rezeptionsästhetischer,

erzählthematischer und textontologischer Paradigmawechsel

\section{ZWEITER TEIL: TYPOLOGIE}

Der Leser als Souverän: Rainer Maria Rilkes »Die Aufzeichnungen des Malte Laurids Brigge« und Carl Einsteins »Bebuquin oder die

Dilettanten des Wunders«

Die Welt als Spielfeld reiner Möglichkeit: Franz Kafkas »Der Proceß« und Robert Musils »Der Mann ohne Eigenschaften«

Die Preisgabe des Erzählten als Fiktion: Thomas Manns »Joseph und seine Brüder« und Max Frischs »Mein Name sei Gantenbein«

\section{DRITTER TEIL: ENTWICKLUNG}

Elemente der Moderne im deutschen Roman seit 1900

Perspektivismus im Zeit- und Gesellschaftsroman

Der diskursive Roman und der Roman-Essay

Gegenwelten oder Die Unterminierung der Realität

Weltverlust und Subjektivismus

Die Erfindung der erzählten Welt

Möglichkeitswelt: Phantasien, Varianten und Verrätselungen

Surreales, Absurdes und Groteskes

Der Montageroman

Nouveau roman in Deutschland

Typus-Kombinationen

Statt eines Nachworts: Moderne, Postmoderne und Epigonentum im deutschen Roman der Gegenwart

Siglen 